\title{
REVIEW
}

\section{Strange times indeed: the evolving significance of myocardial ischaemia and the dwindling importance of functional imaging}

\author{
Adrian lonescu'
}

\begin{abstract}
The ISCHEMIA trial is only the latest and most compelling link in a chain of evidence that suggests that myocardial ischaemia per se is not an appropriate treatment target for patients with stable coronary artery disease. This review is trying to make sense of the momentous and sometimes contradictory recent developments in the space of imaging for myocardial ischaemia.
\end{abstract}

Keywords: myocardial ischaemia, coronary artery disease, imaging.

Rezumat: Studiul ISCHEMIA este doar cea mai recentă și cea mai convingătoare verigă dintr-un lanț de dovezi, care sugerează că ischemia miocardică per se nu este o țintă corectă în abordarea tratamentului pacienților cu boală arterială coronariană stabilă. Acest articol își propune să clarifice cele cele mai recente și importante, uneori contradictorii, noutăți din domeniul imagisticii ischemiei miocardice.

Cuvinte cheie: ischemia miocardică, boala arterială coronariană, imagistică.

\section{INTRODUCTION}

Myocardial revascularisation is arguably the most dynamic, revolutionary area of cardiology and perhaps of clinical medicine. Starting with the first successful anastomosis of the internal thoracic artery to the right coronary artery on February 25, 1964 by (the largely forgotten) Russian surgeon Vasilii Kolessov', followed in 1968 by Favarolo's saphenous vein coronary artery by-pass grafting (CABG) I operation, and progressing with Gruntzig's 1977 plain old balloon angioplasty (POBA), Loop's report of the efficacy of left internal mammary as CABG conduit (1986), Sigwart's first implant of a balloon-dilatable stent (1986), Sousa's first drug-eluting stent (DES - 1999)2, up to the hybrid algorithm for treating chronic total occlusions (CTO) by percutaneous coronary intervention $(\mathrm{PCl})$ around $2010^{3}$, and with the advent and on-going expansion of intracoronary physiological indices such as FFR ${ }^{4}$ and $\mathrm{iFR}^{5}$, the field of myocardial revascularisation has persistently pushed the limits of what is deemed feasible,

' Morriston Cardiac Centre, Swansea Medical School, UK shattering the barriers of convention and accepted medical wisdom, and reinventing itself successfully countless times.

However, after more than half a century of triumphs, myocardial revascularisation for patients with stable coronary artery disease (CAD) is coming under attack, from multiple angles. Are we about to see its demise in the next few years? And, as imaging specialists, how can we find our way in the rapidly-evolving field of ischaemia imaging?

\section{The conventional paradigm of myocardial} ischaemia and its demise

One of the gratifying features of interventional cardiology is its mechanistic simplicity: a coronary stenosis produces myocardial ischaemia, which is associated with symptoms and adverse outcomes. It follows intuitively that the more extensive the ischaemia, the worse the outcomes, and that relieving the obstruction and thus the ischaemia, will necessarily improve symptoms and outcomes ${ }^{6}$.

$\checkmark$ Contact address:

Adrian lonescu, MD, DM, FRCP, Morriston Regional Cardiac Centre, SA6 6NL, UK.

E-mail: adrian.ionescu@wales.nhs.uk 


\section{Treatment modalities for stable CAD}

$C A B G$ vs. medical treatment. The superiority of $C A B G$ over medical treatment of patients with stable coronary artery disease was established by a meta-analysis covering a relatively small number of 1324 patients assigned to $C A B G$ surgery who had better survival than the 1325 assigned to medical management, between 1972 and $1984^{8}$. However, medical treatment of CAD during that era has almost nothing in common with its contemporary, guideline-directed medical treatment. It is therefore fair to say that we have no data for a comparison of CABG to up-to-date medical treatment of stable coronary disease. Such a trial 'begs' to be done, and would be a very important step in placing the surgical treatment of stable CAD on a solid evidence-basis.

CABG vs. $P C l$. Evidently, patients prefer minimally invasive procedures to major surgery, and $\mathrm{PCl}$ offers a very attractive alternative to open-heart CABG. This situation has the perfect ingredients for a bitter turf war between surgeons and interventionalists ${ }^{9}$ which is exacerbated by a stream of contradictory data: after the initial enthusiasm and unreserved, hurried adoption of DES for off-licence indications, a concerted attack on DES ('the firestorm of Barcelona') ${ }^{10}$ was launched at the World Congress of Cardiology in 2006. The interventional community regrouped and, with the emergence of the Academic Research Consortium, $\mathrm{PCl}$ entered the era of rigorous trial design and analysis", convincingly refuting the accusations that DES sharply increase mortality compared to bare-metal stents $(B M S)^{12}$. In spite of thorough trials ${ }^{13}$ and meta-analyses comparing $\mathrm{PCl}$ to $\mathrm{CABG}$ in various anatomic subsets including the left main stem ${ }^{14,15}$ the controversy is not settled and recriminations between surgeons and interventionists continue, as recently seen in the acrimonious aftermath of the EXCEL trial publication $^{16}$. The choice of the modality of coronary revascularisation remains thus extremely complex, even for patients with diabetes mellitus, for whom conventional wisdom had long established that CABG is superior to $\mathrm{PCl}^{17}$. The number of possible permutations involving coronary anatomy, acuity of presentation, patient characteristics, stent platforms, type and kinetics of drug eluted by the stent, procedural parameters, antiplatelet regimes, and concomitant cardioactive treatments is so large that unequivocal answers to the question ,PCl or CABG?" will still take years to emerge.

$\mathrm{PCl}$ vs. medical treatment. This is perhaps the most intriguing and counterintuitive area, in that increasing proof is accumulating that $\mathrm{PCl}$-based revascularisation of patients with stable CAD confers no benefit over guideline-driven medical therapy. BARI-2D ${ }^{18}$ (BMS in diabetics), STICH ${ }^{19}$ (CABG and surgical LV remodelling in patients with ischaemic LV dysfunction), COURAGE $^{20}$ (patients with stenosis of at least $70 \%$ in at least one proximal epicardial coronary artery and objective evidence of myocardial ischemia) each produced enormous controversy and turmoil in the interventional community because they questioned the universally-accepted and intuitively-compelling ,ischaemic paradigm”, according to which relief of ischaemia would improve quality of life and survival.

Nothing, however, compares to the impact of the two most recent trials, ORBITA and ISCHEMIA.

ORBITA $^{21}$ was the first $\mathrm{PCl}$ trial that used a sham procedure in the control arm. All patients had coronary angiography, but those randomised to medical treatment also had a cath-lab based sham $\mathrm{PCl}$ procedure, so they did not know whether they had received stents or not. This was done in order to remove the powerful placebo effect associated with $\mathrm{PCl}$. The primary endpoint was improvement in treadmill exercise time between inclusion and follow up at sixweeks and there was no difference between patients who received a stent and those who had only a sham procedure. None of the secondary endpoints (peak oxygen uptake, change in exercise time to $1 \mathrm{~mm} \mathrm{ST}$ segment depression, angina CCS class, limitation of exercise, stability and frequency of angina, quality of life scores and Duke Treadmill score) was different between groups. The only parameter that reached marginal statistical significance was an improvement in the wall motion score index by dobutamine stress echo in patients who had stents. These results have subsequently been presented as the „final nail in the coffin of PCl", and made it among the headlines of major news programmes.

ISCHEMIA ${ }^{22}$ is the most expensive medical RCT ever conducted (it cost 100 million USD) ${ }^{23}$ and randomised $>5000$ patients with moderate or severe ischaemia (diagnosed by functional imaging or ETT) and screened by CT coronary angiography to rule out left main stem disease, to revascularisation (approx. 2/3 by $\mathrm{PCl}$ and $\mathrm{I} / 3$ by $\mathrm{CABG}$ ) or medical treatment. Over 5 years there was no difference in the primary endpoint of cardiovascular death, myocardial infarction, resuscitated cardiac arrest, or hospitalization for unstable angina or heart failure (adjusted HR $0.93 ; 95 \% \mathrm{Cl} 0.80$ I.08), no significant differences in other combinations 
of endpoints or the endpoints individually, and there was no subgroup that benefitted from revascularisation. The ISCHEMIA-CKD ${ }^{24}$ study also showed no reduction in cardiac events with an invasive strategy and additionally, no improvement in symptoms or quality of life in patients with chronic renal failure.

Both ORBITA ${ }^{25}$ and ISCHEMIA ${ }^{26}$ have been criticised on multiple fronts but, notwithstanding their imperfections, there is no doubt that, jointly, they have dealt a severe blow to the conventional paradigm of ischaemia in stable CAD, by suggesting that inducible myocardial ischaemia is not, after all, an appropriate target for treatment and therefore for imaging, as relieving ischaemia does not appear to improve outcomes or symptoms in the era of aggressive medical treatment.

What is the cardiac imaging specialist supposed to do in this strange, new and shifting landscape?

\section{Implications for ischaemia imaging of recent trial data}

It would be premature to declare functional imaging for ischaemia dead ${ }^{27}$. Neither ORBITA nor ISCHEMIA were set up to compare the role of different imaging modalities in the management of CAD, so any conclusions about imaging utilisation based on their findings are only preliminary and derivative. It is still very relevant to perform functional imaging in many clinical contexts. For instance, a normal ischaemic imaging test carries a powerful and positive prognostic significance, while an abnormal test can explain symptoms and provide reassurance that a pathway to treatment has opened up. An important key to the correct utilisation of diagnostic imaging is to take into account the pre-test probability of ischaemia, as well as the diagnostic performance of each modality, for instance expressed through receiver-operating characteristics ${ }^{28}$.

\section{Potential impact of ISCHEMIA on clinical practice $^{27}$}

How are we to use the findings of ISCHEMIA in our day-to-day approach to patients with suspected CAD?

One option would be to stop testing for ischaemia altogether, given the futility demonstrated by ISCHEMIA and the other large and well-conducted contemporary RCTs quoted earlier. The pitfall is that without demonstration of ischaemia in the individual patient it is difficult to justify prescribing medical treatment, which involves a multitude of life-long tablets, each with its side-effects. Moreover, with an increasingly well-informed patient population, practitioners may come under increasing pressure from the patients themselves to investigate symptoms with ischaemia imaging or invasive angiography. And how can we be sure there is no LMS disease without further testing?

Another option is to perform CT angiography to rule out LMS disease, and then treat medically if it is absent, without any further investigations. This would replicate the approach shown to be safe and effective in ISCHEMIA; revascularisation would be reserved for those patients (free from LMS disease) who still experience intrusive symptoms while on maximal guideline-driven medical therapy, and would not require further imaging before proceeding to $\mathrm{PCl}$ or $\mathrm{CABG}$. A potential problem with this approach is that a recent study of the external applicability of the ISCHEMIA trial found that only $4 \%$ of patients in a large registry fulfilled ISCHEMIA inclusion criteria ${ }^{26}$; moreover, they had a much lower incidence of major adverse cardiac events (MACE) during follow-up than those outside the ISCHEMIA inclusion criteria. This is the first indication that the type of patient for whom the conclusions of ISCHEMIA apply may not be that easy to find in the 'real world'; clearly further validation is needed before we can apply 'mechanically' the ISCHEMIA algorithm.

Finally, there is the option to continue as before, i.e. only perform invasive angiography if pre-test evidence of ischaemia has been obtained non-invasively. This approach is, however, unlikely to prevail, both because the results of ISCHEMIA reduce the pressure to perform functional imaging, and, more importantly, because FFR and especially the much-simpler-to-perform iFR now allow immediate diagnosis of functionally significant coronary stenoses in the cath lab, where immediate revascularisation can be carried out seamlessly in the same procedure.

\section{Non-invasive imaging methods for diagnosing stable CAD}

Functional imaging tests for the diagnosis of coronary artery disease involve acquisition of data both at rest and during a physiological stress (exercise, vasodilator, inotropic stimulant). They visualise either myocardial perfusion by tracking the rest and stress myocardial distribution of an intravenously-injected tracer, or the response of the myocardium to a relative imbalance between metabolic demand and supply during stress, which will manifest as localised or global myocardial systolic dysfunction - hypo-, a- or dyskinesia of myocardial segments.

By contrast, anatomical imaging visualises the coronary arteries, and ideally should be coupled with some 
form of functional assessment in order to ascertain the significance of stenoses of moderate severity (50$70 \%$ ). Fractional flow reserve (FFR) 4 and instantaneous wave-free ratio (iFR) $)^{5}$ have emerged as invasive ,gold standard" tests for the physiological assessment of coronary artery stenoses. Initially these were exclusively invasive tests, performed to guide $\mathrm{PCl}$, but now hybrid imaging allows the acquisition of a CT coronary angiogram (an anatomical test) coupled with either CT-FFR (based on complex hydrodynamic modelling) and/or perfusion imaging (based on the direct proportionality of the image ,brightness" to the amount of contrast agent visualised).

In a meta-analysis comparing multiple methods of functional cardiac imaging directly to FFR, MRI had the highest performance for diagnosing CAD causing myocardial ischaemia, with lower performance for SPECT and SE. Anatomic imaging (CTCA and invasive coronary angiography) had lower specificity, while functional assessment with stress echo, SPECT, and CT-FFR increased diagnostic accuracy ${ }^{28}$. However, CT perfusion imaging and CT-FFR are not yet widely available or fully validated.

Technical aspects of the non-invasive methods for diagnosing inducible myocardial ischaemia are shown in Table $\mathrm{I}^{29}$ and a metanalysis-based comparison of their diagnostic performance in Table $2^{30}$.

\section{Differential impact of test strategy on patient outcomes}

Initial research on the diagnostic performance of ischaemia imaging focused on reproducibility, sensitivity, specificity and similar metrics of the tests. Lately, research has appeared on the effect that the choice of test has on the final outcome/type of treatment for the patient. This is an intriguing concept - why would the diagnostic test sequence impact the outcome? After all, regardless of the pathway by which we arrive at the diagnosis, one would hope that each specific
Table 2. Diagnostic performance of imaging modalities for the diagnosis of inducible myocardial ischaemia (modified from reference 30 )

\begin{tabular}{|l|l|l|}
\hline Modality & Sensitivity & Specificity \\
\hline Exercise ECG & 0.66 & 0.75 \\
\hline Stress Echo & 0.80 & 0.84 \\
\hline SPECT & 0.61 & 0.84 \\
\hline Real-time myocardial contrast TTE & 0.75 & 0.52 \\
\hline CMR & 0.87 & 0.91 \\
\hline CCTA & 0.78 & 0.86 \\
\hline
\end{tabular}

condition is consistently and appropriately treated in everybody who has it.

Nevertheless, this seems to be the case indeed, reflecting the wide variation in practices and the role that immeasurable variables such as „clinical judgement" play in the choice of investigations and treatments. For instance, in the SCOT HEART trial ${ }^{31}$, patients with stable chest pain who also had CTCA on top of standard care experienced a significantly lower rate of death from coronary heart disease or nonfatal myocardial infarction at 5 years than those receiving standard care alone, without a higher rate of coronary angiography or coronary revascularization. The explanation seems to be that patients in the CTCA group had received preventive and anti-anginal drugs more frequently that the controls.

In PROMISE ${ }^{32}$ I 0.003 patients with chest pain were randomly assigned to a strategy of initial anatomical testing with coronary computed tomographic angiography or to functional testing (exercise electrocardiography, nuclear stress testing, or stress echocardiography). The composite primary end point was death, myocardial infarction, hospitalization for unstable angina, or major procedural complication. Over a followup of 2 years, the CTCA-first strategy offered no benefits over the functional testing strategy, with identical

\begin{tabular}{|l|l|l|l|}
\hline \multicolumn{2}{|l|}{ Table I. Overview of functional imaging modalities. Modified from reference 29} \\
\hline Method & Limitations & Advantages & Spatial resolution \\
\hline SPECT & $\begin{array}{l}\text { Radiation, spatial resolution, limited } \\
\text { quantification, atteuation }\end{array}$ & Widely available, well tested, robust and reproducible & $10 \times 10 \times 10 \mathrm{~mm}$ \\
\hline PET & $\begin{array}{l}\text { Lower spatial resolution of quantitative } \\
\text { I5O2-water PET }\end{array}$ & Gold standard for perfusion imaging, best for quantitation & $4 \times 4 \times 4 \mathrm{~mm}$ \\
\hline MRI & $\begin{array}{l}\text { Costly, not widely available, interference } \\
\text { from pacemakers, claustrophobia, poor } \\
\text { image quality in irregular heart rhythms }\end{array}$ & $\begin{array}{l}\text { Non-invasive biopsy, unlimited field of view, extensive } \\
\text { assessment of cardiac and intrathoracic structures }\end{array}$ & $1 \times 2 \times 6-8 \mathrm{~mm}$ \\
\hline ECHO & Variable image quality, operator-dependence & $\begin{array}{l}\text { Versatility, repeatability, widely available, relatively simple and } \\
\text { cheap setup }\end{array}$ & IxI-3x3-6mm \\
\hline
\end{tabular}


occurrence of the primary endpoints in both arms of the trial, but with more invasive coronary angiograms in the CTCA arm. The divergence from the results of the smaller SCOT HEART trial has been accounted for by the significantly lower prevalence of obstructive CAD in PROMISE (half the level in SCOT HEART) as well as by the directionally opposing effects of myocardial infarction and hospitalisation for unstable angina, leading to an overall neutral effect ${ }^{33}$. Moreover, the PROMISE investigators did report that CCTA was associated with a $34 \%$ relative reduction in all-cause death and myocardial infarction at 12 months.

Finally, three meta-analyses ${ }^{31,34,35}$ agree that, compared with functional stress testing, the use of CCTA appears to associate with a lower incidence of myocardial infarction but also with an increase in the usage of invasive coronary angiography, revascularization procedures (of which some may have been un-necessary), CAD diagnoses, and new prescriptions for aspirin and statins. Despite these differences, CCTA overall is not associated with a reduction in all-cause mortality or cardiac hospitalizations.

\section{If not myocardial ischaemia, what should be our imaging target in CAD now?}

In the aftermath of ISCHEMIA this has become an existential question for imaging specialists. The tenets of half a century of practice based on the conventional wisdom that relieving myocardial ischaemia improves outcomes are crumbling away - what is there to replace them?

\section{Plaque burden, vulnerable plaque}

CCTA. Increasingly, the emphasis is shifting from the assessment of myocardial ischaemia and of coronary stenoses to that of the overall amount of atheroma in the coronary tree. Coronary calcium scoring by EBCT has long been validated as a risk-prediction tool, but recently it was shown that "plaque burden, not stenosis per se, is the main predictor of risk for CVD events and death. Thus, patients with a comparable calcified atherosclerosis burden, generally, carry on a similar risk for CVD events regardless of whether they have non-obstructive or obstructive CAD"36.

Conversely, in patients with a calcium score of zero, it is the presence or absence of obstructive CAD that correlates with outcomes ${ }^{37}$.

Plaque remodelling (PR) (defined as diameter of plaque 10\% larger than reference vessel), low attenuation plaque (LAP) (less than $30 \mathrm{HU}$ ), a ,napkin ring” appearance and spotty calcification are CT features of vulnerable plaque, a predictor of $\mathrm{ACS}^{38,39}$.
Myocardial ischaemia and its dwindling significance

CMR. Although CMR can image the proximal coronary arteries ${ }^{40}$ as well as plaque composition (high intensity plaque in particular appears to correlate with $A C S^{41}$ ) with good accuracy ${ }^{42}$, there is much less data on CMR than on CT for prognosticating outcomes based on arterial appearances in patients with CAD. This is partly explained by the poorer spatial resolution of CMR compared with CT (although acquisition at $3 \mathrm{~T}^{43}$ seems to resolve the problem) and partly by the longer, more laborious acquisition protocols. Moreover, $C T$ acquires genuine 3D volumes, while CMR reconstructs volumes by acquisition of sequential slices, „stitched" together by reference to the $\mathrm{R}$ wave on the ECG, thus being vulnerable to respiratory motion and to irregular heart rhythms. However, the wellvalidated ability of stress-perfusion CMR to offer high specificity and high sensitivity assessment of myocardial ischaemia means it has the potential to offer the mythical non-invasive „one-stop shop”, which delivers anatomical and functional data with a single investigation, the real 'Holy Grail' of imaging.

\section{Perivascular adipose tissue}

There is increasing understanding of the „toxicity” of adipose tissue for vascular health, by the release of cytokines and of other biologically active mediators that promote atheroma formation and plaque instability. The fat attenuation index (FAl) is a novel parameter that can be measured by $C T$ in the epicardial adipose tissue (EAT) around the coronaries and correlates to plaque instability and outcomes ${ }^{44}$. In the CRISP CT study ${ }^{45}$ patients with abnormally high perivascular FAI had $\sim 9$ times higher risk for cardiac mortality. This improved prediction of mortality was well above the current state of the art assessment of risk using CTCA, including clinical risk factors, calcium score, the extent of coronary atherosclerosis and the presence of high-risk plaque features.

\section{CONCLUSIONS}

Under the pressure of data from randomised controlled trials, the mechanistic paradigm that has underpinned the practice of cardiology in the space of stable coronary artery disease is shifting. The call to drop our ,obsession with coronary luminology”, articulated by Topol and Nissen in 199566, has finally borne fruit, as we move from ,detecting the vulnerable plaque to managing the vulnerable patient" ${ }^{\prime \prime}$. Our focus in imaging is shifting from stenoses, inducible myocardial ischaemia and plaques to atheroma burden and its metabolic activity in conjunction to that of the perivas- 
cular adipose tissue. A new era of atheroma and metabolic-focused imaging is starting, and as an imaging community we should be ready to embrace it.

$\begin{array}{ll}\text { Abbreviations } \\ \text { ACS } & \text { acute coronary syndrome } \\ \text { BMS } & \text { bare-metal stent } \\ \text { CABG } & \text { coronary artery bypas graft } \\ \text { CAD } & \text { coronary artery disease } \\ \text { CCS } & \text { Canadian Cardiac Society } \\ \text { CMR } & \text { Cardiac magnetic resonance } \\ \text { CTCA } & \text { computer-tomography coronary angiogram } \\ \text { CVD } & \text { cardiovascular disease } \\ \text { DES } & \text { drug-eluting stent } \\ \text { EAT } & \text { epicardial adipose tissue } \\ \text { EBCT } & \text { electron-beam computer tomography } \\ \text { ETT } & \text { exercise tolerance test } \\ \text { FAI } & \text { fat attenuation index } \\ \text { FFR } & \text { fractional flow reserve } \\ \text { HU } & \text { Hounsfield units } \\ \text { IFR } & \text { instantaneous wave-free ratio } \\ \text { LAP } & \text { low attenuation plaque } \\ \text { LMS } & \text { left main stem } \\ \text { LV } & \text { left ventricle } \\ \text { MACE } & \text { major adverse cardiac events } \\ \text { MRI } & \text { magnetic resonance iaging } \\ \text { PCI } & \text { perccutaneous coronary intervention } \\ \text { PR } & \text { plaque remodelling } \\ \text { RCT } & \text { randomised controlled trial } \\ \text { SPECT } & \text { single-photon emission computer tomography }\end{array}$

\section{References:}

I. Melly L, Torregrossa G, Lee T, Jansens J-L, Puskas JD. Fifty years of coronary artery bypass grafting. J Thorac Dis 2018;10: 1960-1967.

2. Iqbal J, Julian Gunn J, Serruys PW. Coronary stents: historical development, current status and future directions: Brit Med Bulletin 2013; 106: 193-211.

3. Michael T, Karmpaliotis D, Brilakis E et al. Procedural outcomes of revascularization of chronic total occlusion of native coronary arteries (from a Multicenter United States Registry). Am. J. Cardiol. 2013: II 2, 488-92.

4. Pijls NHJ, de Bruyne B, Peels $\mathrm{K}$ et al. Measurement of Fractional Flow Reserve to Assess the Functional Severity of Coronary-Artery Stenoses. N Engl J Med 1996; 334: 1703-8.

5. Davies JE, Sen S,. Dehbi H-M et al. Use of the Instantaneous Wave-free Ratio or Fractional Flow Reserve in PCl. N Engl J Med 2017;376:1824-34.

6. Sharir T, Hollander I, Hemo B, Tsamir J, Yefremov N, Bojko A, et al. Survival benefit of coronary revascularization after myocardial perfusion SPECT: The role of ischemia. J Nucl Cardiol 2019;50:1296-306.

7. Yusuf S, Zucker D, Peduzzi P, Fisher LD, Takaro T, Kennedy JW, Davis K, Killip T, Passamani E, Norris R, et al. Effect of coronary artery bypass graft surgery on survival: overview of 10 -year results from randomised trials by the Coronary Artery Bypass Graft Surgery Trialists Collaboration. Lancet. 1994;344:563-70.

8. Yusuf S, Zucker D, Peduzzi P, Fisher LD, Takaro T, Kennedy JW, Davis K, Killip T, Passamani E, Norris R, et al. Effect of coronary artery bypass graft surgery on survival: overview of 10 -year results from randomised trials by the Coronary Artery Bypass Graft Surgery Trialists Collaboration. Lancet. 1994;344:563-70.
9. Kaufman J. The Uncut Version. New York Oct. 2003. https://nymag. com/nymetro/health/columns/strongmedicine/n_93II / accessed on line 23/0I/2021.

10. Garg S, Serruys PW. Drug-eluting stents: a reappraisal. Heart. 2010; 96:489-493.

II. Cutlip DE, Windecker S, Mehran R. et al, on behalf of the Academic Research Consortium. Clinical End Points in Coronary Stent Trials: A Case for Standardized Definitions. Circulation. 2007;1 15:23442351.

12. Serruys PW, Daemen J. The SCAAR registry or the Swedish yo-yo. Eurolntervention. 2007; 3: 297-300.

13. Serruys PW, Morice M-C, Kappetein P et al for the SYNTAX Investigators. Percutaneous Coronary Intervention versus CoronaryArtery Bypass Grafting for Severe Coronary Artery Disease. NEJM. 2009; 360 96I-72.

14. Ahmad Y, Howard JP, Ahran D et al. Mortality after drug-eluting stents vs. coronary artery bypass grafting for left main coronary artery disease: a meta-analysis of randomized controlled trials. Eur Heart J. 4I: 3228-35.

15. Gaudino M, Hameed I, Farkouh M et al. Overall and Cause-Specific Mortality in Randomized Clinical Trials Comparing Percutaneous Interventions With Coronary Bypass Surgery: A Meta-analysis. JAMA Intern Med. 2020;180:1638-46.

16. https://www.medscape.com/viewarticle/934827 accessed online 22/0I/2021.

17. Bangalore S, Zenati MA. The "Fragility" of Mortality Benefit of Coronary Artery Bypass Graft Surgery in Diabetics. JACC 2019; 73: 639 . 42.

18. Chaitman BR, Hardison RM, Adler D, et al. The Bypass Angioplasty Revascularization Investigation 2 Diabetes randomized trial of different treatment strategies in type 2 diabetes mellitus with stable ischemic heart disease: impact of treatment strategy on cardiac mortality and myocardial infarction. Circulation 2009;120: 2529-2540.

19. Jones RH, Velazquez EJ, Michler RE et al. Coronary Bypass Surgery with or without Surgical Ventricular Reconstruction. N Engl J Med 2009; 360:1705-1717.

20. William E Boden WEI, Robert A O'Rourke RA, Koon K Teo KK, et al. Optimal medical therapy with or without $\mathrm{PCl}$ for stable coronary disease. N Engl J Med 2007; 356: I503-16.

21. Al-Lamee R, Thompson D, Dehbi HM et al. Percutaneous coronary intervention in stable angina (ORBITA): a double-blind, randomised controlled trial. Lancet. 2018; 39: 3I-40.

22. Maron DJ, Hochman JS, Reynolds HR Initial Invasive or Conservative Strategy for Stable Coronary Disease. N Engl J Med 2020; 382: 1395 1407.

23. https://blogs.bmj.com/bmj/2020/0I/07/harlan-m-krumholz-theischemia-trial-post-presentation-and-pre-publication/, accessed on 24/0I/202I.

24. Bangalore S, Maron DJ, O'Brien SM et al. Management of Coronary Disease in Patients with Advanced Kidney Disease. N Engl J Med 2020; 382:1608-1618.

25. Jackson M, Zaman A. ORBITA: What Goes Around, Comes Around... Or Does It? Interventional Cardiology Review 2018; 13(3):135-6.

26. DeLuca L, Uguccioni M, Meessed J et al. External applicability of the ISCHEMIA trial: an analysis of a prospective, nationwide registry of patients with stable coronary artery disease. Eurolntervention 2020; 16:e966-e973.

27. Shaw L, Kwong R, Nagel $E$ et al. Cardiac Imaging in the Post-ISCHEMIA Trial Era: A Multisociety Viewpoint. JACC Cardiovasc Imaging. 2020; I3:1815-1833.

28. Danad I, Raijmaker PG, Driessen $S$ et al. Comparison of Coronary CT Angiography, SPECT, PET, and Hybrid Imaging for Diagnosis of Ischemic Heart Disease Determined by Fractional Flow Reserve. JAMA Cardiol. 2017; 2:1 100-II07.

29. Dewey, M., Siebes, M., Kachelrieß, M. et al. Clinical quantitative cardiac imaging for the assessment of myocardial ischaemia. Nat Rev Cardiol 17, 427-450 (2020).

30. Outcomes of non-invasive diagnostic modalities for the detection of coronary artery disease: network meta-analysis of diagnostic ran- 
domised controlled trials Siontis GCM, Mavridis D, Greenwodd JP et al. BMJ 20।8;360:k452.

3I. SCOT-HEART Investigators: Newby DE, Adamson PD, Berry $C$ et al. Coronary CT Angiography and 5-Year Risk of Myocardial Infarction. N Engl J Med 2018 379:924-933.

32. Douglas PS, Hoffman U, Patel MR et al. Outcomes of Anatomical versus Functional Testing for Coronary Artery Disease. N Engl J Med 2015;372:1291-300.

33. Adamson PD, Newby DE. The SCOT-HEART Trial. What we observed and what we learned. J Cardiovasc Comput Tomogr. 2019; 13: 54-58.

34. Foy AJ, Dhruva SS, Peterson B, Mandrola J, Morgan DJ, Redberg RF. Coronary Computed Tomography Angiography vs Functional Stress Testing for Patients With Suspected Coronary Artery Disease: A Systematic Review and Meta-analysis. JAMA Intern Med. 2017; 177: |623-1631.

35. Bittencourt M.S., Hulten E.A., Murthy V.L. Clinical outcomes after evaluation of stable chest pain by coronary computed tomographic angiography versus usual care: a meta-analysis. Circulation: Cardiovasc. Imag. 2016;9(4):e004419.

36. Mortensen MB, Dzaye O, Steffensen FH et al. Impact of Plaque Burden Versus Stenosis on Ischemic Events in Patients With Coronary Atherosclerosis. J Am Coll Cardiol 15; 76: 2803-28I3.

37. Villines TC, Hulten EA, Shaw LJ et al. Prevalence and severity of coronary artery disease and adverse events among symptomatic patients with coronary artery calcification scores of zero undergoing coronary computed tomography angiography: results from the CONFIRM (Coronary CT Angiography Evaluation for Clinical Outcomes: An International Multicenter) registry. J Am Coll Cardiol 2011;58:2533-40.

38. Motoyama S, Sarai M, Harigaya H, et al. Computed Tomographic Angiography Characteristics of Atherosclerotic Plaques Subsequently Resulting in Acute Coronary Syndrome. J Am Coll Cardiol 2009;54:49-57.
39. Motoyama S, Ito H, Sarai M, et al. Plaque Characterization by Coronary Computed Tomography Angiography and the Likelihood of Acute Coronary Events in Mid-Term Follow-Up. J Am Coll Cardiol 2015;66:337-46.

40. Yoon YE, Kitagawa K, Kato S, et al. Prognostic Value of Coronary Magnetic Resonance Angiography for Prediction of Cardiac Events in Patients With Suspected Coronary Artery Disease. J Am Coll Cardiol 20I2;60:2316-22.

41. Kawasaki T, Koga S, Koga N, et al. Characterization of hyperintense plaque with non-contrast $\mathrm{T}(\mathrm{I})$-weighted cardiac magnetic resonance coronary plaque imaging: comparison with multi-slice computed tomography and intravascular ultrasound. JACC Cardiovasc Imaging 2009;2:720-8.

42. Botnar RM, Stuber M, Kissinger KV, et al. Non-invasive coronary vessel wall and plaque imaging with magnetic resonance imaging. Circulation 2000;102:2582-7.

43. Gharib AM, Abd-Elmoniem KZ, Ho VB, et al. The feasibility of 350 um spatial resolution coronary magnetic resonance angiography at 3 T in humans. Invest Radiol 2012;47:339-45.

44. Antoniades C, Kotanidis CP, Berman DS. State-of-the-art review article. Atherosclerosis affecting fat: What can we learn by imaging perivascular adipose tissue? J Cardiovasc Comput Tomogr. 2019; I3: 288-296.

45. Oikonomou E.K., Marwan M., Desai M.Y. Non-invasive detection of coronary inflammation using computed tomography and prediction of residual cardiovascular risk (the CRISP CT study): a post-hoc analysis of prospective outcome data. Lancet 2018; 392: 929-939.

46. Topol EJ, Nissen SE. Our Preoccupation With Coronary Luminology: The Dissociation Between Clinical and Angiographic Findings in Ischemic Heart Disease Circulation 1995; 92: 2333-42.

47. Arbab-Zadeh A, Fuster V. From Detecting the Vulnerable Plaque to Managing the Vulnerable Patient. JACC State-of-the-Art Review. J Am Coll Cardiol 2019;74:1582-93. 